\title{
A highly sensitive Raman method for selective cyanide detection based on evaporated cuprous iodide substrate $\dagger$
}

\author{
C. V. Gopal Reddy, $\ddagger^{a}$ Fei Yan, $\hbar^{a}$ Yan Zhang ${ }^{a}$ and Tuan Vo-Dinh ${ }^{* a b}$ \\ Received 4th February 2010, Accepted 10th March 2010 \\ First published as an Advance Article on the web 20th April 2010 \\ DOI: $10.1039 / \mathrm{c0ay00085j}$
}

\begin{abstract}
A strong interaction between cyanide anion and copper(I) cation in combination with non-resonant Raman fingerprinting allows the selective sensing of aqueous free cynanide with high sensitivity to parts per billion (ppb)-level.
\end{abstract}

Cyanide is a very common pollutant. It is a constituent of vehicle exhaust and cigarette smoke, and is utilized in many industrial processes such as gold mining, electroplating, printing, textiles and leather manufacturing. ${ }^{1}$ One of the most rapidly acting lethal poisons known to humankind, cyanide can kill within seconds to hours depending on the cyanide levels and exposure patterns. For example, exposure to an airborne cyanide concentration of 90 parts per million (ppm) for $30 \mathrm{~min}$ is likely to be incompatible with life, while death may result from minutes of exposure at $300 \mathrm{ppm}^{2}$ Long-term exposure to lower concentrations of cyanide in occupational settings can result in a variety of symptoms related to central nervous system effects. $^{3}$ Guidelines for human exposure to cyanide have been developed by several agencies worldwide. The U.S. Environmental Protection Agency (EPA) requires that the residual cyanide in treated industrial wastewater be less than $1 \mathrm{ppm}$ before they are allowed to be discharged into aquatic ecosystems. ${ }^{4}$ The concern of a possible terrorist attack using cyanide, as well as the gradual awareness of cyanide poisoning in fire victims, has resulted in a renewed interest in the quick diagnosis of cyanide, which is critical for timely and effective treatment. ${ }^{2}$ Thus, it is essential to develop rapid, sensitive, selective and accurate methods for aqueous cyanide determination.

Over the years, numerous analytical techniques for the detection of free cyanide have been developed, these include spectrophotometic, ${ }^{5}$ electrochemical, ${ }^{6}$ spectroscopic, ${ }^{7}$ capillary electrophoresis, ${ }^{8}$ chemiluminescence $^{9}$ and chromatographic detection ${ }^{10}$ approaches. However, some of the detection strategies either involve the use of synthetic probes that are not easily accessible by other groups, the formation of hydrogen cyanide (HCN), or inherit shortcomings such as low sensitivity, poor reproducibility, and limited selectivity. Further, most of these techniques, while they may well be great analytical tools in a laboratory setting, are generally not suitable for field detection of environmental cyanides due to the requirement of

\footnotetext{
a'Fitzpatrick Institute for Photonics, Department of Biomedical Engineering, Duke University, Durham, NC, 27708, USA. E-mail: tuan. vodinh@duke.edu; Fax: +1-919-613-9145; Tel: +1-919-660-8520

${ }^{b}$ Department of Chemistry, Duke University, Durham, NC, 27708, USA $\dagger$ Electronic supplementary information (ESI) available: Further experimental details. SEM, and XRD characterization of evaporated cuprous iodide films, and Raman measurement conditions. See DOI: $10.1039 / \mathrm{c} 0$ ay00085j

\$ Contributed equally to this work.
}

additional reagents and tedious sample pretreatment or measurements.

Here we present a unique approach that employs a non-resonant Raman scattering detection of cyanide after its retention by semiconducting cuprous iodide (CuI) thin films.

In this study, $\mathrm{CuI}$ thin films with a variety of thickness ranging from $100 \mathrm{~nm}$ to $1 \mu \mathrm{m}$ were deposited on the silicon wafer slides by thermal evaporation, and characterized by SEM and XRD.† Elongated grains with sizes ranging from $20 \mathrm{~nm}$ to $1 \mu \mathrm{m}$ were observed in SEM images of CuI on silicon slides. As demonstrated in Fig. 1, evaporated $\mathrm{CuI}$ thin film underwent significant morphological changes after reacting with a $10 \mathrm{ppm}$ cyanide solution for $5 \mathrm{~min}$. $\mathrm{CuI}$ has a solubility constant $\left(K_{\mathrm{sp}}\right)$ of $1.27 \times 10^{-12}$, while $\mathrm{CN}^{-}$displaces $\mathrm{I}^{-}$ and reacts violently with copper(I) $\mathrm{Cu}^{+}$ions to form $\mathrm{CuCN}$ $\left(K_{\mathrm{sp}}=3.47 \times 10^{-20}\right)$. Both $\mathrm{CuI}$ and $\mathrm{CuCN}$ are essentially insoluble in water, this property makes our approach especially advantageous in
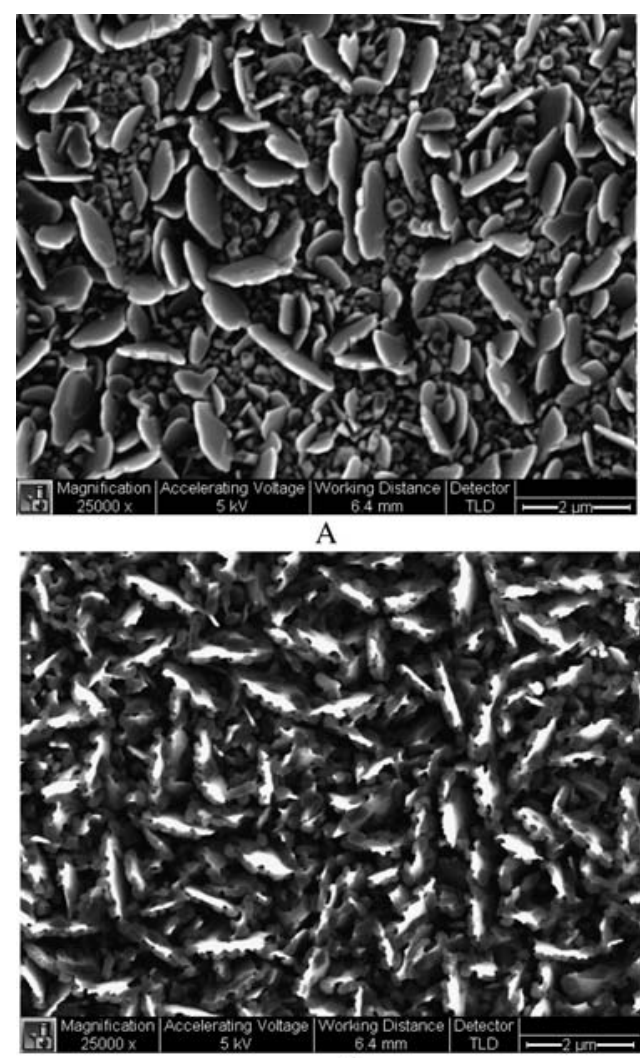

B

Fig. 1 SEM images of evaporated cuprous iodide thin films before (Top) and after (Bottom) reacting with $10 \mathrm{ppm} \mathrm{CN}^{-}$for $5 \mathrm{~min}$. Scale bar: $2 \mu \mathrm{m}$. 
determining cyanide contents in complex matrices such as industrial waste water and mining reservoirs etc.

Raman spectroscopy is well known for its specificity in chemical and biological analyses, and offers some distinct advantages over other spectroscopic methods such as fluorescence and infrared spectroscopy. The vibrational information provided by Raman spectroscopy is very specific for chemical bonds and thus for unique structures in molecules; it can therefore provide an optical fingerprint used to identify a molecule. ${ }^{11}$ As shown in Fig. 2A, the Raman spectra of cyanide are dominated by an intense, broad peak at $2171 \mathrm{~cm}^{-1}$ attributed to the $\mathrm{C} \equiv \mathrm{N}$ stretch. This same mode occurs at $2080 \mathrm{~cm}^{-1}$ in Raman spectra of cyanide solutions, and the frequency shift in Raman spectra is attributed to a strong surface interaction between copper(I) and cyanide. $\mathrm{CuCN}$ salt is known to be a white powder, and it does not absorb light in the visible region (400$800 \mathrm{~nm}$ ), as a matter of fact, it only has two distinct absorbance peaks at $237 \mathrm{~nm}$ and $208 \mathrm{~nm}$, respectively. ${ }^{12}$ The excitation source we used in our Raman measurements is a He-Ne laser (633 nm), hence our observed signals were strictly coming from non-resonant Raman scattering.

While the following three copper-cyanide complexes also may form in aqueous solution: $\left[\mathrm{Cu}(\mathrm{CN})_{2}\right]^{-},\left[\mathrm{Cu}(\mathrm{CN})_{3}\right]^{2-}$ and $\left[\mathrm{Cu}(\mathrm{CN})_{4}\right]^{3-}$, it has been well established that the distribution of these complexes at

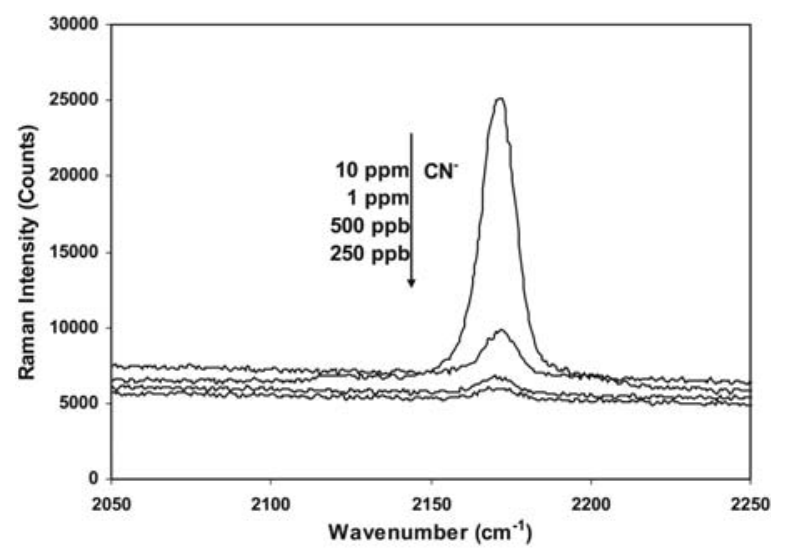

A

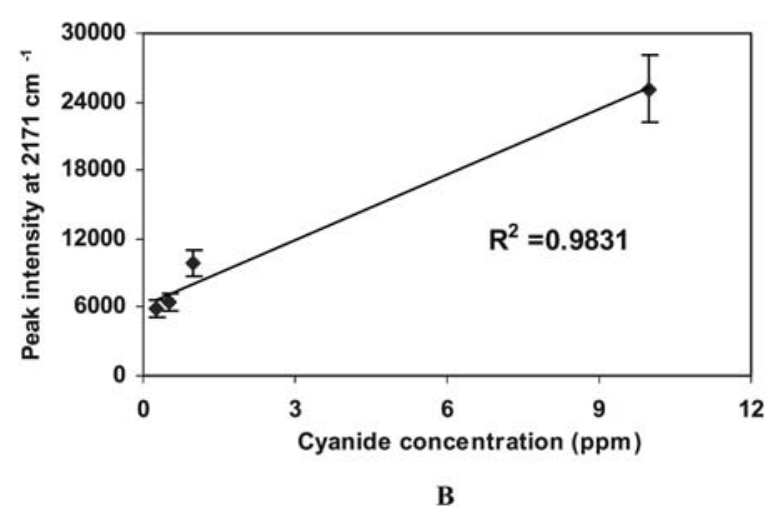

Fig. 2 A) Raman spectra of $\mathrm{CuI}$ thin film substrates after reacting with $\mathrm{CN}^{-}$of different concentrations, and B) Calibration curve obtained from the peak intensity at $2171 \mathrm{~cm}^{-1}$. Each $\mathrm{CuI}$ thin film was incubated with cyanide solutions for $5 \mathrm{~min}$, and rinsed with water before they were examined by Raman scattering. equilibrium is highly dependent upon the $\mathrm{CN} / \mathrm{Cu}$ molar ratio. ${ }^{12}$ In our case, we were dealing with cyanide ions at ppb to ppm levels, hence, there will not be any excessive cyanide available to form any compounds with higher complexes such as $\mathrm{Cu}(\mathrm{CN})_{4}{ }^{3-}$ beyond $\mathrm{CuCN}$. This point was also supported by the Raman data we presented, whereby the single cyanide stretching line at $2171 \mathrm{~cm}^{-1}$ indicates that there is only one copper cyanide complex (i.e., $\mathrm{CuCN}$ ) is present, which agrees well with a previous report. ${ }^{13}$

Peak intensities of the characteristic $\mathrm{C} \equiv \mathrm{N}$ stretching at $2171 \mathrm{~cm}^{-1}$ were used for the quantitative evaluation of cyanide. For a single experimental run, Raman scattering was performed on multiple spots on several cuprous iodide films, which were evaporated at the same time, after dipping them into cyanide solutions of different concentrations for 5 min (while stirring). All Raman spectra were obtained on a Renishaw InVia Raman microscope equipped with an ultra low noise charge-couple device (CCD) detector. $\dagger$ In this system, $632.8 \mathrm{~nm}$ radiation from a Helium-Neon laser was used with an excitation power of $\sim 50 \mathrm{~mW}$. Signal collection is performed at $180^{\circ}$ with respect to the incident laser beam. The Raman spectral region of interest for cyanide, 2050-2250 $\mathrm{cm}^{-1}$, was recorded using a 30-s integration time, and 3 accumulations. The calibration curve for potassium cyanide $(\mathrm{KCN})$ was obtained using $0.25,0.50,1$ and $10 \mathrm{ppm}$ concentrations (Fig. 2B). Each evaporated CuI thin film substrate from the same batch was immersed in a $200-\mathrm{mL}$ Erlenmeyer beaker containing cyanide solutions for $5 \mathrm{~min}$ while stirring. Each data point represents the average of triplicate measurements from the same $\mathrm{CuI}$ thin film after reacting with the same cyanide solution, with $1 \sigma$ standard deviation. A nice linear response was found within the concentration range from $250 \mathrm{ppb}$ to $10 \mathrm{ppm}$. The limit of detection was determined to be $\sim 100 \mathrm{ppb}$ from $3 \sigma$ standard deviations above the background. Common interfering anions such as $\mathrm{SO}_{4}{ }^{2-}, \mathrm{ClO}_{4}{ }^{-}$, and $\mathrm{NO}_{3}{ }^{-}$, and $\mathrm{PO}_{4}{ }^{3-}$ did not affect the $\mathrm{CN}^{-}$detection even at much high concentration levels.

In summary, we present here the use of cuprous iodide thin films which were evaporated on silicon wafer slides as a capturing element for the direct detection of cyanide without sample pretreatment. The copper(I) ions react with $\mathrm{CN}^{-}$ion, and the resulting $\mathrm{CuCN}$ can be easily detected by normal (non-resonant or surface-enhanced) Raman scattering. Even lower detection limit can be expected to achieve by varying the coating thickness of $\mathrm{CuI}$, or the integration of silver nanostructure-based surface-enhanced Raman scattering, as well as increasing the incubation time with the cyanide-containing solutions. Coupled with portable Raman instruments, ${ }^{14}$ our approach can be easily adapted to be used for the field monitoring of aqueous free cyanide.

The authors are grateful to the Lord Foundation of Duke University for financial support, and to the Shared Materials Instrumentation Facility (SMIF) at Duke University for use of the SEM and XRD. We also thank Michelle Gignac for her technical assistance.

\section{Notes and references}

1 R. R. Dash, A. Gaur and C. Balomajumder, J. Hazard. Mater., 2009, $163,1$.

2 L. Nelson, J. Emerg. Nurs., 2006, 32(4), S8.

3 R. Neufeld, J. Greenfield and B. Rieder, Water Res., 1986, 20, 633.

4 Cyanide in Water and Soil: Chemistry, Risk, and Management. ed. D. A. Dzombak, D. A. Dzombak, R. S. Ghosh, and G. M. WongChong. Taylor \& Francis Group: Boca Raton, FL. 2006. 
5 (a) P. Lundquist, H. Rosling and B. Sorbo, Clin. Chem., 1985, 31, 591; (b) C. Siontorou and D. P. Nikolelis, Anal. Chim. Acta, 1997, 355, 227; (c) H. Sulistyarti, T. J. Cardwell, M. D. Luque de Castro and S. D. Kolev, Anal. Chim. Acta, 1999, 390, 133; (d) G. Drochioiu, Talanta, 2002, 56, 1163; (e) F. H. Zelder and C. Mannel-Croise, Chimia, 2009, 63, 58.

6 (a) S. Chung, S. Nam, J. Lim, S. Park and J. Yoon, Chem. Commun., 2009, 2866; (b) K. Yea, S. Lee, J. B. Kyong, J. Choo, E. K. Lee, S. Joo and S. Lee, Analyst, 2005, 130, 1009; (c) A. M. Westley and J. Westley, Anal. Biochem., 1989, 181, 190; (d) A. Taheri, M. Noroozifar and M. Khorasani-Motlagh, J. Electroanal. Chem., 2009, 628, 48.

7 (a) L. Shang, L. H. Jin and S. J. Dong, Chem. Commun., 2009, 3077; (b) P. A. Mosier-Boss and S. H. Lieberman, Appl. Spectrosc., 2003 , 57, 1129; (c) W. R. Premasiri, R. H. Clarke, S. Londhe and M. E. Womble, J. Raman Spectrosc, 2001, 32, 919; (d) W. B. Knighton, E. C. Fortner, A. J. Midey, A. A. Viggiano, S. C. Herndon, E. C. Wood and C. E. Kolb, Int. J. Mass Spectrom., 2009, 283, 112; (e) Y. Yan, H. Li and M. L. Myrick, Appl. Spectrosc., 2000, 54, 1539.

8 (a) Q. Lu, G. E. Collins, T. Evans, M. Hammond, J. Wang and A. Mulchandani, Electrophoresis, 2004, 25, 116; (b) S. Chinica, S. akanaka, N. Takayama, N. Tsuji, S. Takou and K. Ueda, Anal. Sci., 2001, 17, 649.
9 (a) A. Amine, M. Alafandy, J. M. Kauffmann and M. N. Pekli, Anal. Chem., 1995, 67, 2822; (b) J. L. Lee and I. Karube, Anal. Chim. Acta, 1995, 313, 69; (c) N. Sadeg and H. Belhadj-Tahar, Toxicol. Environ. Chem., 2009, 91, 419; (d) M. Aguilar, A. Farrán and V. Marti, J. Chromatogr., A, 1997, 778, 397.

10 (a) A. Sano, M. Takezewa and S. Takitani, Anal. Chim. Acta, 1989, 225, 351; (b) D. Scilia, S. Rubio, D. Pérez-Bendito, N. Maniasso and E. A. G. Zagatto, Analyst, 1999, 124, 615; (c) S. Kage, T. Nagata and K. Kudo, J. Chromatogr., B: Biomed. Sci. Appl., 1996, 675, 27.

11 (a) T. Vo-Dinh, TrAC, Trends Anal. Chem., 1998, 17, 557; (b) Raman Spectroscopy for Chemical Analysis. Ed. R. L. McCreery, Wiley, 2000; (c) M. D. King, S. Khadka, G. A. Craig and M. D. Mason, J. Phys. Chem. C, 2008, 112, 11751.

12 G. C. Lukey, J. S. J. van Deventer, S. T. Huntington, R. L. Chowdhury and D. C. Shallcross, Hydrometallurgy, 1999, 53, 233

13 G. Laufer, T. F. Schaaf and J. T. Huneke, J. Chem. Phys., 1980, 73 , 2973.

14 (a) F. Yan and T. Vo-Dinh, Sens. Actuators, B, 2007, 121, 61; (b) L. X. Quang, C. Lim, G. H. Seong, J. Choo, K. J. Dob and S. Yoo, Lab Chip, 2008, 8, 2214. 